\title{
Using Shortened Systematic Strategic Planning (SSP) Working Model for the Development of a Strategic Plan of an Entrepreneurial Business-Case Study
}

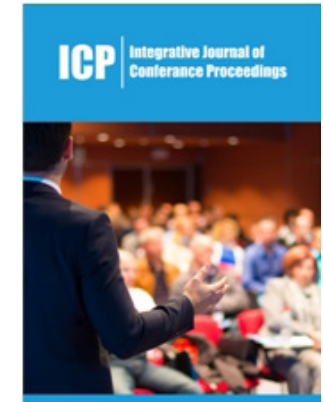

*Corresponding author: Hakan Butuner, Industrial Management and Engineering, President, Turkey

Submission: 侮 May 14, 2019

Published: 眥August 06, 2019

Volume 2 - Issue 1

How to cite this article: Hakan B, Emre Y, Evrim V, Sinan D. Using Shortened Systematic Strategic Planning (SSP) Working Model for the Development of a Strategic Plan of an Entrepreneurial Business-Case Study. Int J Conf Proc.2(1). ICP.000523.2019.

Copyright@ Hakan Butuner, This article is distributed under the terms of the Creative Commons Attribution 4.0 International License, which permits unrestricted use and redistribution provided that the original author and source are credited.

\author{
Hakan Butuner ${ }^{1 *}$, Emre Yılmaz ${ }^{2}$ Evrim Varan ${ }^{2}$ and Sinan Dibakoğlu ${ }^{2}$ \\ ${ }^{1}$ Industrial Management and Engineering, President, Turkey \\ ${ }^{2}$ MBA Students, Turkey
}

\begin{abstract}
Where strategic analysis tools are explained, this is most frequently done conceptually rather than their actual application in strategic planning. Shortened systematic strategic planning (SSP) consists of a pattern of stepwise procedure for straight-forward planning, and the fundamentals involved in any strategic planning project. SSP has been applied to and tested on different businesses' subject issue and has been generated by the composition of the cause-and-effect relations of them. The intention here is to provide a new perspective and benefit for the strategic planners by introducing this new systematic methodology and demonstrating its implementation on an entrepreneurial and new business called Visual Co. Accordingly, let shortened version of SSP easily understood and universally applied to any small- and medium-size businesses. Additionally, you are guided how to identify in what circumstances you might use its specific tools and how to target them directly at achieving effective results. The data that are used in this case are fictitious and only help for this study. Though, the given case does not cover all the steps of a typical systematic strategic plan and use all the recommended techniques, it still reflects the basics.
\end{abstract}

Keywords: Strategic planning; Strategic management; Systematic strategic planning; Strategy; Case study in strategic planning

\section{Introduction}

\section{Shortened systematic strategic planning (SSP)}

Before beginning with strategic planning, businesses must have articulated their missions and visions, and identified their basic policies [1]. Strategic plan helps the business to establish its objectives, goals, as well as the decisions to achieve these objectives and goals. Thus, a strategic plan provides guidance for the preparation of functional plans, such as marketing, finance, production, etc., and business budget in such a manner that they reflect the objectives, goals, and main strategies of the strategic plan during the implementation phase, as well as for basing resource allocation on priorities [2]. Systematic Strategic Planning is the pattern of procedures by which an organization defines its status, opportunities, long-term goals, and the strategies for which to achieve them. SSP is based on the principles of Planning by Design (PxD) which is generated by Muther [3]. A strategic plan includes the fundamentals, and the basis on which any systematic strategic planning must rest are competitive advantages, scenarios and strategies.

Competitive advantages: Competitive advantages are fundamental A. Because of investigating internal and external factors, weaknesses and strengths of the organization determined. Based on the comparison of the strengths with market conditions, the unique strengths, that is, competitive advantages of the organization are determined.

Scenarios: Scenarios are fundamental B. Scenario analysis is made on external factors-macro economic analysis, industry analysis, etc. By this analysis, negative and positive scenarios are determined. These scenarios help to predict the industry's future. 
Strategies: Strategies are fundamental C. Strategies are the fundamental that helps the organization to define how to reach to the opportunity that is brought out by matching fundamental A with fundamental B. This fundamental characterizes the process that organization should follow to reach the opportunity and guides the organization about how it should be done. The use of shortened SSP version is more suitable for the development of strategic plans for small- and medium-size businesses (SMEs). This paper is intended to briefly explain how each step of shortened SSP pattern can be applied on a given case. The case study presented in here is an entrepreneurial and new business. The data that are used in this case are fictitious and only help for this study. Though, the given case does not cover all the steps of a typical systematic strategic plan and use all the recommended techniques, it still reflects the basics.

\section{Systematic pattern of strategic planning}

The newly generated Shortened SSP is a six-step methodology intended to identify the three fundamentals. Figure 1 illustrates shortened version of SSP.

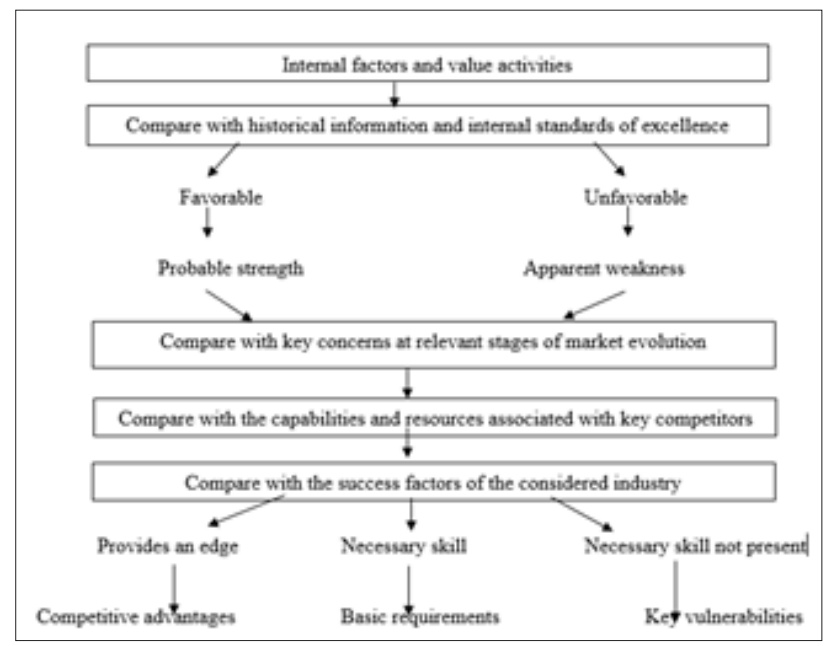

Figure 1: Shortened systematic strategic planning.

Investigating environmental and internal conditionsclarification of current status: The aim of the first section of SSP is to answer the question, where are we? This requires a comprehensive status analysis. During and after status analysis, the internal strengths and weaknesses of the organization, and the positive and negative developments originating from the external factors are identified.

\section{Internal Analysis}

Internal status analysis begins with a brief history of the business. Therefore, the business should examine its past performance to isolate key internal contributors to favorable (or unfavorable) results. Diagnosing a business' key strengths and weaknesses requires the adoption of a disaggregated view of the business. Examining the business across distinct functional areas (such as, overall management, human resources, operations/ technology, marketing, finance and accounting) is one way to disaggregate the business for internal analysis purposes. The purpose is to identify the potential of the business taking into consideration its existing performance and problems.

\section{Environmental Analysis}

Environmental analysis considers the general trends in the world, changes in the environment in which the business operates and particularly the expectations of the group served by the industry. Environmental analysis does not only identify status, but also lays the basis for future forecasts or creation of scenarios.
While making these assessments, the global and domestic trends in the sector/sub-sector in which the organization operates are discussed.

\section{Intention of environmental analysis:}

A. To determine the developments and trends in the macroeconomical (demographic, economical, judicial-political, technological, sociocultural) environment that effects the business and its industry at most. This review should primarily be conducted at global scale, and then at regional and country scales.

B. The effects of trends and developments within these variables on the industry are analyzed with respect to customers', governments', financial institutions', suppliers', shareholders', and employees' points of view.

C. To understand the powers that effect competition in the industry (new businesses, customers, suppliers, substitutes, competitors, government, financial institutions, etc.) [4]. When one of these groups has a higher power, this will have negative implications for the industry, whereas a lower power will have positive implications.

D. To foresee the trends that these powers would create in the industry [5] stated that each industry passes through the phases of introductory, growth, maturity, and finally regression. The phase that the industry is in facilitates the estimation of impacts and trends of powers defined in competition analysis. 


\section{Comparison of Status and Identification of Competitive Advantages}

The organization's strengths and weaknesses are compared with the key factors in the market development phases, capacities, and resources of main competitors and the industry's success factors, to identify competitive advantages. Figure 2 summarizes the development of a business [6]. A factor is considered a competitive advantage if it is something the business does (or has in the future capacity to do) particularly well relative to the abilities of existing or potential competitors. A firm gains competitive advantage by performing these strategically crucial factors for cheap or better than its competitors.

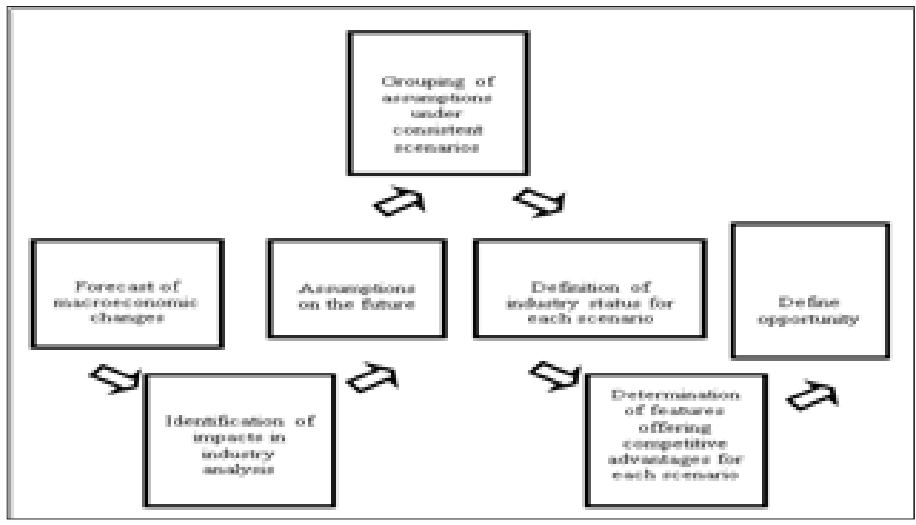

Figure 2: Competitive advantages and success factors.

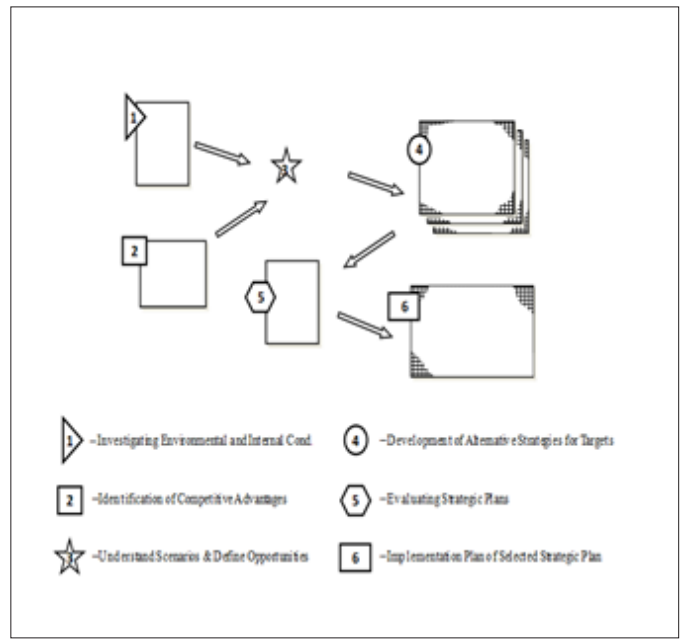

Figure 3: Procedure of identifying opportunities.

Understand Scenarios and Define Opportunities (Figure 3). Using the trends to be revealed by the environmental analysis, it is possible to anticipate how the field of business in which we operate or plan to enter will evolve in the future. It is intended to find the factors that would affect and change the outlook mostly in the status and anticipated future, based on the results obtained from environmental analysis. Then, the scenarios to be created by trends revealed by environmental analysis for the industry must be developed; that is, alternative scenarios must be developed for the future.

Finally, to identify the business' potential opportunities, the organization's competitive advantages need to be matched with the potential positive (attractive) scenarios in the industry. Besides market attractiveness of each scenario, you also need to take some view of the organization's competitive position with respect to the scenario [7].

\section{Identification of strategic objectives and main goals and development of alternative strategies}

The parameters constituting the assumed opportunities need to be laid down as strategic objectives and main goals. Strategic objectives are the conceptual results that the organization aims at achieving within a certain timeframe. Strategic objectives and main goals answer the question what do we want to achieve?

Main goals are specific and measurable sub objectives specified for achievement of strategic objectives. Main goals can be classified as financial and market goals, such as target markets, product range, sales volume and profitability for the planned period, regional concentration, etc.; and operational goals, such as organization, investment goals, labor turnover rate, environmental standards, technology and equipment choice, quality and performance standards, long-term capacity plans, etc. 
It is necessary to analyze what should be done and how should they be done to attain opportunities and thus achieve goals, as well as to identify alternative strategies. Determination of a suitable strategy for a business begins in identifying the opportunities and risks in its environment. While evaluating the opportunities defined based on analyses conducted, various strategies we can implement come out [8]:

A. You should have a single strategy for a single opportunity.

B. If there are multiple opportunities, you can have multiple strategies.

Based on using both the techniques of Generic Competitive Strategies [4] and Components of Strategy [9], the corresponding Grand Strategies can be identified [6]. For example; concentration, market development, product development, innovation, horizontal integration, vertical integration, joint venture, concentric diversification, etc.

\section{Evaluating strategic plans and selecting the best}

Here you select the strategic plan most suitable for your organization. To do this, you make an evaluation of the alternatives based on qualitative factors [3]. For example; synergy, competitive advantages, flexible organization structure, market orientation, critical success factors, etc. Even if the best strategy is selected, contingency plans are still necessary for the selected strategy in a risky environment. A sensitivity analysis needs to be conducted [10], taking into consideration the possibility that basic assumptions and parameters do not come out as expected and the measures considered to be taken in this respect need to be identified.

\section{Implementation plan and control}

The implementation plan is a tool that gets strategic plans underway. The implementation plan required to be created to answer the question how can we reach our target destination? in the systematic of strategic planning must be coherent with the whole of strategic plan [11]. This is the step when action plans are prepared to identify by whom, how, and when the strategy created to achieve strategic objective and goals will be implemented within the business. This step also involves the preparation of budgets for utilization of resources required for the realization of action plans.

\section{Visual Co}

Visual Co. has a vision that is to become a totally respected regional company for those looking for a breathing space and/ or trying to carry themselves to a better mood by capturing and influencing the imaginations. Its mission is to be a continual challenger against the leaders of the entertainment industry and make the consumers' moods better by sensorial joy assets [12].

\section{Clarification of Current Status}

Internal analysis: Functional approach is used for internal analysis which is shown in Table 1. In the table,
A. The strengths are marked as (+)
B. The weaknesses are marked as (-) (Table 1)

Table 1: Functional approach worksheet.

\begin{tabular}{|c|c|c|}
\hline & & Strengths/Weaknesses \\
\hline \multirow{13}{*}{ 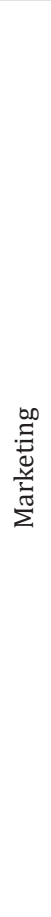 } & Firm's products /services; breadth of product line & + \\
\hline & Concentration of sales in a few products or to a few customers & - \\
\hline & Ability to gather needed information about markets & - \\
\hline & Market share or submarket shares & - \\
\hline & Product / service mix and expansion potential & + \\
\hline & Channels of distribution: number, coverage and control & - \\
\hline & Effective sales organization & + \\
\hline & Product / service image, reputation and quality & + \\
\hline & Imaginative, efficient and effective sales promotion and advertising & - \\
\hline & Pricing strategy and pricing flexibility & - \\
\hline & $\begin{array}{l}\text { Procedures for digesting market feedback and } \\
\text { developing new products, services or markets }\end{array}$ & + \\
\hline & After-sale service and follow up & - \\
\hline & Goodwill/brand loyalty & - \\
\hline
\end{tabular}




\begin{tabular}{|c|c|c|}
\hline \multirow{13}{*}{ 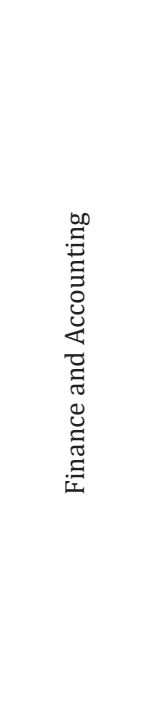 } & Ability to raise short-term capital & + \\
\hline & Ability to raise long-term capital: debt/equity & - \\
\hline & Corporate-level resources & - \\
\hline & Cost of capital relative to industry and competitors & - \\
\hline & Tax considerations & - \\
\hline & Relations with owners, investors and stockholders & + \\
\hline & Leverage positions & + \\
\hline & Cost of entry and barriers to entry & + \\
\hline & Price-earnings ratio & + \\
\hline & Working capital; flexibility of capital structure & - \\
\hline & Effective cost control, ability to reduce costs & + \\
\hline & Financial size & - \\
\hline & $\begin{array}{l}\text { Efficient and effective accounting system for cost, } \\
\text { budget and profit planning }\end{array}$ & + \\
\hline \multirow{12}{*}{ 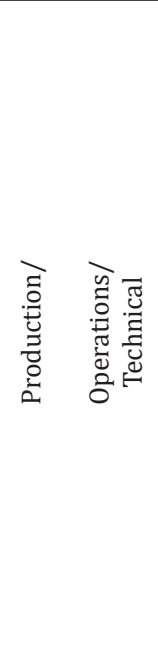 } & Raw materials cost and availability & - \\
\hline & Inventory control systems; inventory turnover & - \\
\hline & Location of facilities; layout and utilization of facilities & + \\
\hline & Economies of scale & - \\
\hline & Technical efficiency of facilities and utilization of capacity & - \\
\hline & Effective use of subcontracting & + \\
\hline & Degree of vertical integration, value added and profit margin & + \\
\hline & Efficiency and cost / benefit of equipment & + \\
\hline & Effective operation control procedures & + \\
\hline & $\begin{array}{l}\text { Cost and technological competencies } \\
\text { relative to industry and competitors }\end{array}$ & - \\
\hline & Research and development/technology/innovation & + \\
\hline & Patents, trademarks and similar legal protection & + \\
\hline \multirow{9}{*}{ 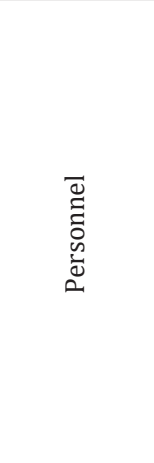 } & Management personnel & + \\
\hline & Employees' skill and morale & - \\
\hline & Labor relations compared to industry and competition & + \\
\hline & Efficient and effective personnel policies & + \\
\hline & Effective use of incentives to motivate performance & + \\
\hline & Ability to level peaks and valleys of employment & + \\
\hline & Employee turnover and absenteeism & + \\
\hline & Specialized skills & + \\
\hline & Experience & - \\
\hline \multirow{10}{*}{ 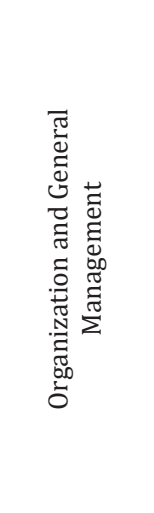 } & Organizational structure & + \\
\hline & Firm's image and prestige & + \\
\hline & Firm's record for achieving objectives & + \\
\hline & Organization of communication system & + \\
\hline & Overall organizational control system & + \\
\hline & Organizational climate, culture & + \\
\hline & Use of systematic procedures and techniques in decision making & - \\
\hline & Top-management skill, capacities and interest & + \\
\hline & Strategic planning system & + \\
\hline & Interorganizational synergy & + \\
\hline
\end{tabular}


Environmental Analysis

\section{Macroeconomic analysis}

Table 2: Macroeconomic analysis form.

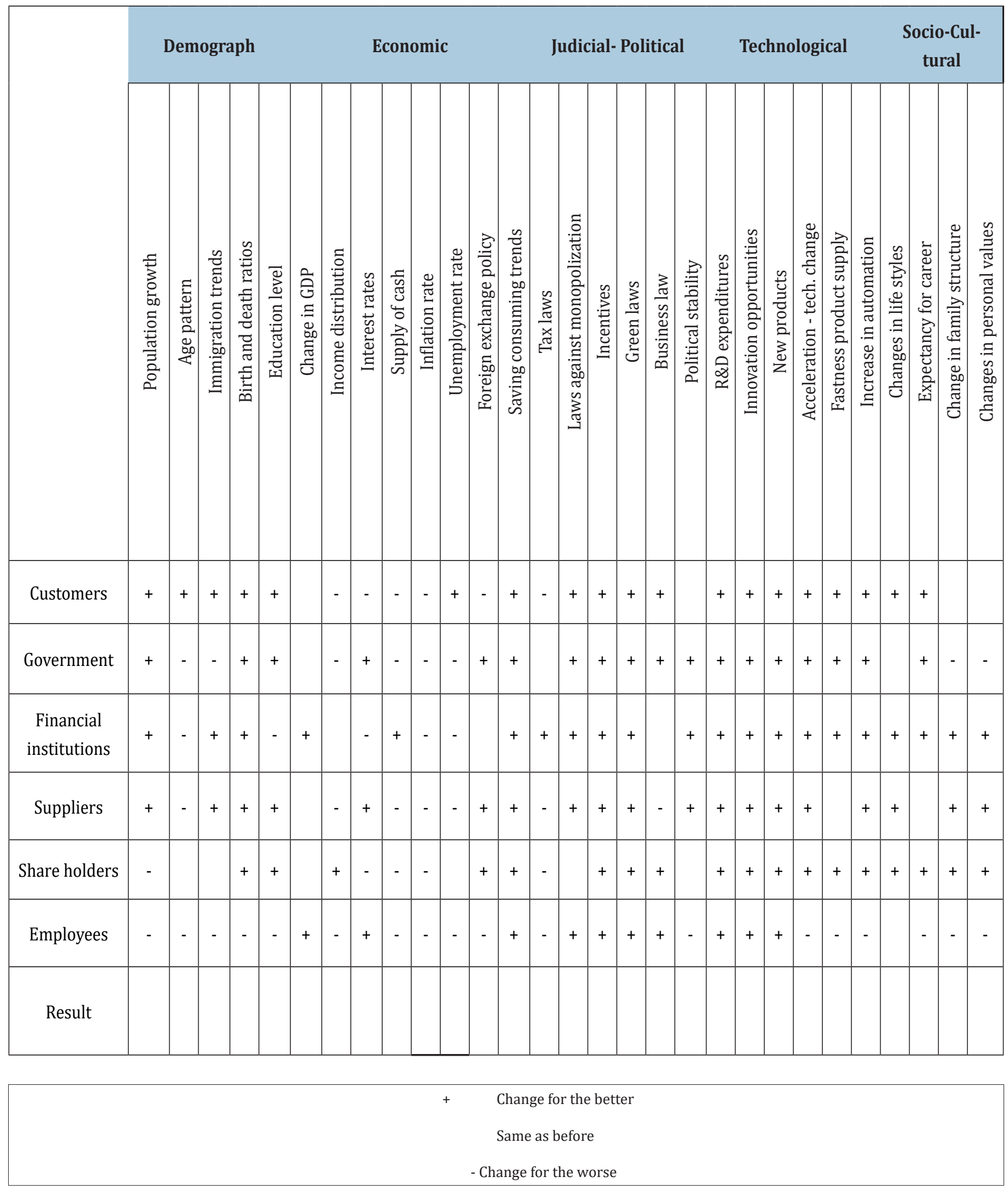


Table 2 shows the macroeconomic analysis form that summarizes the status of the variables with respect to customers', government's', financial institutions', suppliers', shareholders' and employees' points of view. If the macroeconomic factor will
A. Turn into a better condition, then mark as +
B. Remain unchanged, then mark as blank
C. Turn into a worse condition, then mark as -

\section{Customers' point of view}

A. Demographic and technological factors will change in a better way.

B. Economic factors, except unemployment rate and saving/ consuming trends, will be worse.

C. Gross domestic product (GDP) will be stable.

D. Legal and political factors, except tax laws, will be better, and there will be political stability.

E. Socio and cultural factors, such as life styles and career expectancy, will be better.

F. Family structures and personal values/beliefs will remain unchanged.

\section{Governments' point of view}

A. Demographic factors, except age pattern and immigration trends, will be better.

B. Economic factors, except interest rates, foreign exchange policy; and saving/consuming trends, will be worse.

C. GDP will remain unchanged.

D. Legal and political factors, except tax laws and technological factors, will be better.

E. There will be no change in tax laws.

F. Sociocultural factors, such as family structures and personal values/beliefs, will be worse.

G. Lifestyles will remain unchanged.

\section{Financial institutions' point of view}

A. Demographic factors, except age pattern and education level, will be better.

B. Economic factors, except interest rates, inflation rate, and unemployment rate, will be better.

C. The foreign exchange policy and income distribution will remain unchanged.

D. Legal and political factors, except business law and technological factors, will be better.
E. There will be no change in business law.

F. All sociocultural factors will be better.

\section{Suppliers' point of view}

A. Demographic factors, except age pattern, will be better.

B. Economic factors except interest rates, foreign exchange policy and saving/consuming trends will be worse.

C. GDP will remain unchanged.

D. Legal and political factors, except business and tax laws, will be better.

E. Sociocultural factors, except career expectancy, will be better.

F. Technological factors will be better.

\section{Shareholders' point of view}

A. Demographic factors, except population growth, will be better.

B. Age pattern and immigration trends of the population will remain unchanged.

C. Economic factors, except income distribution, foreign exchange policy, and saving/consuming trends, will be worse.

D. The unemployment rate and GDP will remain unchanged.

E. Legal and political factors, except tax laws, will be better.

F. Law against monopolization and political stability will not change.

G. All technological and sociocultural factors will be better.

\section{Employees' point of view}

A. All demographic factors will be worse.

B. Economic factors, except GDP, interest rates and saving/ consuming trends, will be worse.

C. Legal and political factors, except tax laws and political stability, will be better.

D. Technological factors, except research and development expenditures, innovation opportunities, and new products, will be worse.

E. Sociocultural factors, except changes in life style, will be worse.

\section{Competition analysis}

Table 3 shows the status of the existing firms, threats of new companies, and competitive power of customers and suppliers. 
Table 3: shows the status of the existing firms, threats of new companies, and competitive power of customers and suppliers.

\begin{tabular}{|c|c|c|c|c|c|c|c|c|c|c|c|c|c|c|c|c|c|c|c|c|c|c|}
\hline & \multicolumn{5}{|c|}{ Firms in the industry } & \multicolumn{6}{|c|}{ Threats of new companies } & \multicolumn{6}{|c|}{$\begin{array}{c}\text { Competitive power of cus- } \\
\text { tomers }\end{array}$} & \multicolumn{5}{|c|}{$\begin{array}{l}\text { Competitive power of sup- } \\
\text { pliers }\end{array}$} \\
\hline & 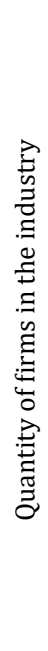 & 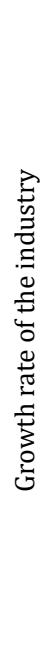 & 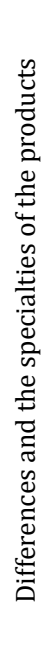 & 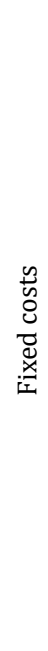 & 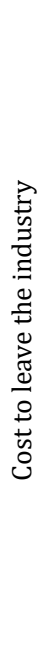 & 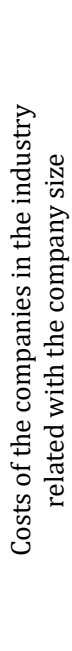 & 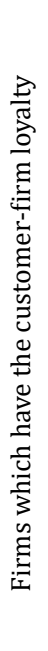 & 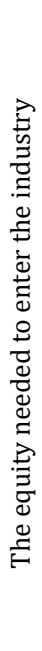 & 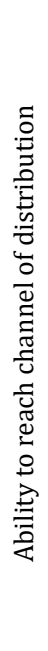 & 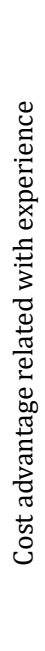 & 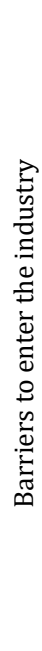 & 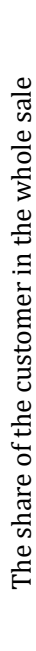 & 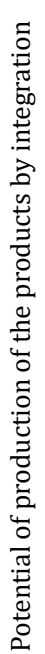 & 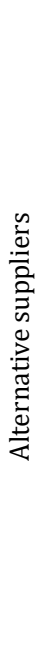 & 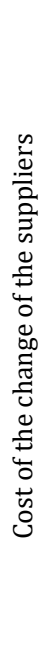 & 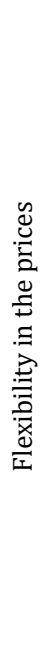 & 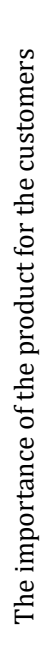 & 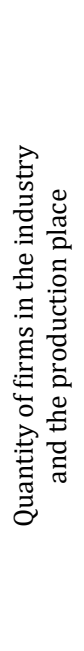 & 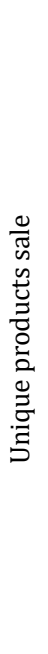 & 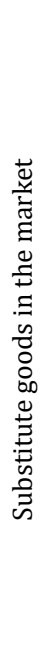 & 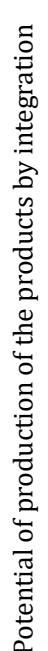 & 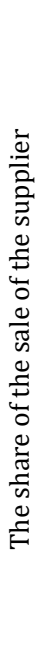 \\
\hline High & 0 & 0 & 1 & 1 & 0 & 0 & 0 & 1 & 1 & 0 & 0 & 0 & 0 & 0 & 1 & 0 & 0 & 0 & 1 & 1 & 0 & 0 \\
\hline Avg & 0 & 1 & 0 & 0 & 1 & 1 & 0 & 0 & 0 & 1 & 0 & 0 & 1 & 0 & 0 & 1 & 0 & 0 & 0 & 0 & 1 & 1 \\
\hline Low & 1 & 0 & 0 & 0 & 0 & 0 & 1 & 0 & 0 & 0 & 1 & 1 & 0 & 1 & 0 & 0 & 1 & 1 & 0 & 0 & 0 & 0 \\
\hline
\end{tabular}

\section{Rivalry}
A. Number of firms in the industry is few.
B. Industry growth rate is uniform.
C. Product differences and specialties are high.
D. Fixed costs of the firms are high and cost of leaving industry is reasonable.

Industry Life Cycle

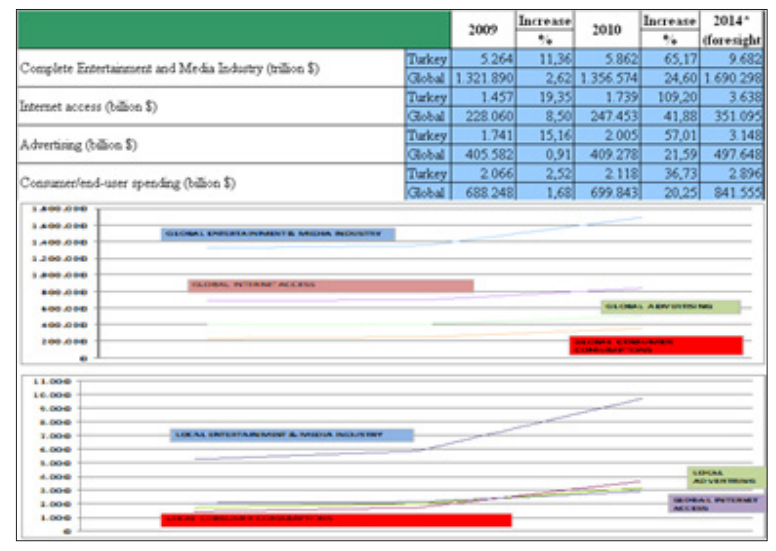

Figure 4: Industry life cycle.

\section{New players}

A. High-capital investment is necessary to enter the industry.

B. Hard to reach to the channels of distribution.

\section{Customers and suppliers}

A. Cost of changing suppliers is high.

B. Prices are flexible.

C. Number of suppliers is few. 
Due to its dependency on technological development, new segments of the media and entertainment industry are constantly being introduced. Entertainment and media are evolved in a highly dynamic nature. Entertainment and media industry revenues were $\$ 1.321 .890$ billion in 2009 , and grew further to $\$ 1.356 .574$ billion in 2010 , and it is expected to be $\$ 1.690 .298$ billion in 2014 globally. Internet advertising will be the fastest growing media during the next five years. Advertising will increase from $\$ 2.005$ billion in 2010 to $\$ 3.148$ billion in 2014 in Turkey. Entertainment and media industry are in a growth stage, as shown in (Figure 4).

\section{Competitive advantages, success factors, weaknesses}

Table 4: Comparison table.

\begin{tabular}{|c|c|c|c|c|}
\hline & & Industry & $\begin{array}{l}\text { Main } \\
\text { Comp }\end{array}$ & Visual co \\
\hline \multirow{13}{*}{ 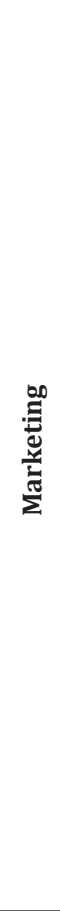 } & Firm's products /services; breadth of product line & + & + & + \\
\hline & Concentration of sales in a few products or to a few customers & - & - & - \\
\hline & Ability to gather needed information about markets & - & - & - \\
\hline & Market share or submarket shares & + & + & - \\
\hline & Product / service mix and expansion potential & - & - & + \\
\hline & Channels of distribution: number, coverage and control & + & + & - \\
\hline & Effective sales organization & - & + & + \\
\hline & Product / service image, reputation and quality & + & + & + \\
\hline & Imaginative, efficient and effective sales promotion and advertising & - & - & - \\
\hline & Pricing strategy and pricing flexibility & - & - & - \\
\hline & $\begin{array}{l}\text { Procedures for digesting market feedback and } \\
\text { developing new products, services or markets }\end{array}$ & + & + & + \\
\hline & After-sale service and follow up & - & - & - \\
\hline & Goodwill/brand loyalty & - & - & - \\
\hline \multirow{13}{*}{ 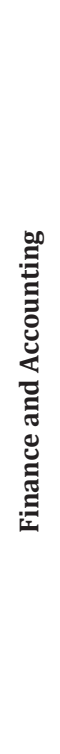 } & Ability to raise short-term capital & - & + & + \\
\hline & Ability to raise long-term capital: debt/equity & - & + & - \\
\hline & Corporate-level resources & - & - & - \\
\hline & Cost of capital relative to industry and competitors & + & + & - \\
\hline & Tax considerations & - & - & - \\
\hline & Relations with owners, investors and stockholders & + & + & + \\
\hline & Leverage positions & + & + & + \\
\hline & Cost of entry and barriers to entry & + & + & + \\
\hline & Price-earnings ratio & - & + & + \\
\hline & Working capital; flexibility of capital structure & - & + & - \\
\hline & Effective cost control, ability to reduce costs & - & - & + \\
\hline & Financial size & + & + & - \\
\hline & $\begin{array}{l}\text { Efficient and effective accounting system for cost, } \\
\text { budget and profit planning }\end{array}$ & - & + & + \\
\hline
\end{tabular}




\begin{tabular}{|c|c|c|c|c|c|}
\hline \multirow{12}{*}{\multicolumn{2}{|c|}{ 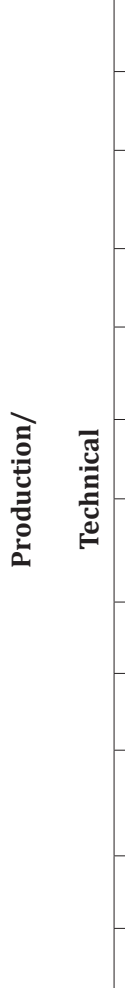 }} & Raw materials cost and availability & - & - & - \\
\hline & & Inventory control systems; inventory turnover & - & - & - \\
\hline & & Location of facilities; layout and utilization of facilities & + & + & + \\
\hline & & Economies of scale & - & + & - \\
\hline & & Technical efficiency of facilities and utilization of capacity & - & - & - \\
\hline & & Effective use of subcontracting & - & - & + \\
\hline & & Degree of vertical integration, value added and profit margin & + & + & + \\
\hline & & Efficiency and cost / benefit of equipment & + & + & + \\
\hline & & Effective operation control procedures & + & + & + \\
\hline & & $\begin{array}{l}\text { Cost and technological competencies } \\
\text { relative to industry and competitors }\end{array}$ & - & + & - \\
\hline & & Research and development/technology/innovation & - & + & + \\
\hline & & Patents, trademarks and similar legal protection & + & + & + \\
\hline \multirow{9}{*}{\multicolumn{2}{|c|}{ 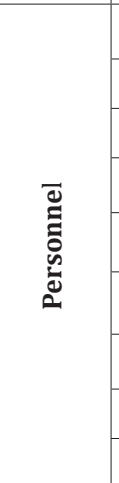 }} & Management personnel & - & - & + \\
\hline & & Employees' skill and morale & + & + & - \\
\hline & & Labor relations compared to industry and competition & - & - & + \\
\hline & & Efficient and effective personnel policies & + & + & + \\
\hline & & Effective use of incentives to motivate performance & + & + & + \\
\hline & & Ability to level peaks and valleys of employment & - & - & + \\
\hline & & Employee turnover and absenteeism & + & + & + \\
\hline & & Specialized skills & - & + & + \\
\hline & & Experience & - & - & - \\
\hline \multirow{10}{*}{\multicolumn{2}{|c|}{ 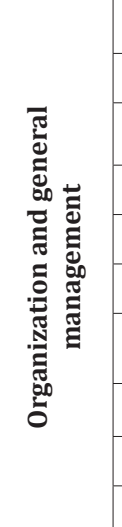 }} & Organizational structure & + & + & + \\
\hline & & Firm's image and prestige & - & + & + \\
\hline & & Firm's record for achieving objectives & + & + & + \\
\hline & & Organization of communication system & + & + & + \\
\hline & & Overall organizational control system & - & - & + \\
\hline & & Organizational climate, culture & + & + & + \\
\hline & & Use of systematic procedures and techniques in decision making & - & - & - \\
\hline & & Top-management skill, capacities and interest & - & - & + \\
\hline & & Strategic planning system & + & - & + \\
\hline & & Interorganizational synergy & + & - & + \\
\hline
\end{tabular}

Table 4 is a comparison table that ends-up with competitive advantages, success factors and weaknesses of the firm, defined as follows:

Competitive advantages: Factors providing the business with an edge compared to its main competitor and industry average, that is, the ones that have plus sign only on the Visual Co. column.
Success factors: Factors that are important capabilities for the business to have but are also typical of every viable competitor; do not represent a potential source of any strategic advantage.

Key vulnerabilities: Factors on which the business currently lacks the necessary skill, knowledge, or resources to compete effectively, and shown as minus sign on the Visual Co. column (Table 4). 


\section{Scenarios and opportunities}

Based on the outcome of environmental analysis, the concluded positive and negative scenarios for the entertainment and media industry are summarized below. Additionally, the concluded business opportunities for Vision Co., by matching its competitive advantages with the potential positive sceanarios of the industry, are listed below as well.

\section{Positive scenarios}

Product/service mix and expansion potential: The industry is new, and yet products are highly demanded.

Product/service image, reputation and quality: Despite the intensive use of technology; a lot of work is based on creativity, so there will be many opportunities to offer quality products to the market.

Ability to raise short-term capital: Investors are willing to invest in this technology-intensive, promising, and rapidly growing industry. Cost of entry and barriers to entry is high for new players.

\section{Negative scenarios}

A. In media and especially in animation sector, because of the narrow price-range, if costs increase, they cannot be charged to the end user due to the nature of sales agreements.

B. Creation of visual products is mainly based on detailed studies, and this may decrease efficiency and increase costs.

C. Because of the creativity-based structure and high variety of products, difficulties may arise in using standard procedures and techniques.

\section{Business opportunity}

A. Easy to gain a competitive position, as potential entrepreneurs cannot enter the market due to prohibitive cost barriers.

B. Cultural richness in the region can be applied to product design and should be used as an opportunity to increase the market share.

\section{Main strategies}

Based on the determined opportunities of Vision Co., its products will always be perceived as creative and new within the existing market. Product development will be its main strategy (Table 5).

Table 5: Components of strategy.

\begin{tabular}{|c|c|c|c|}
\hline \multirow{2}{*}{ Product } & \multirow{2}{*}{ New } & \multicolumn{2}{|c|}{ Market } \\
\cline { 3 - 4 } & & New & Existing \\
\cline { 3 - 4 } & & Innovation & Product development \\
\cline { 3 - 4 } & \multirow{2}{*}{ Existing } & Market & Market \\
\cline { 3 - 4 } & & Development & Concentration \\
\hline
\end{tabular}

\section{Developing new product features:}

Adapt: Know-how will be brought through strategic alliances and will be adapted to the organization. Being a pioneer in the market will be an advantage for substantial product development.

Modify: The technology and theme (characters, soundtracks, etc.) used will be updated according to the market requirements and changing preferences of customers.

Minify: iPhone applications will be created for its trailers integrated with social media.

Substitute: Its products will be applied to the toys of movies, such as animal characters, etc.

Combine: Selling specially designed (logos, themes, shapes) 3D eyeglasses to movie audiences.

Vision Co. will also focus on differentiation as a strategy, as shown in Table 6 , by using its differentiation as a competitive advantage on a narrow scale market.

Table 6: Generic strategies.

\begin{tabular}{|c|c|c|}
\hline \multirow{4}{*}{$\begin{array}{c}\text { Score } \\
\text { Board }\end{array}$} & Competitive Advantage Cost & Differentiation \\
\cline { 2 - 3 } & Cost leadership & Differentiation \\
\cline { 2 - 3 } & Cost focusing & $\begin{array}{c}\text { Differentiation } \\
\text { focusing }\end{array}$ \\
\hline
\end{tabular}

\section{Conclusion}

The aim of Systematic Strategic Planning (SSP) is to force a consider the future and therefore provides an opportunity to influence the future, or assume a proactive posture, to provide better awareness of needs and environment, to help define and focus on the objectives of the organization. SSP-shortened version consists of a pattern of six steps for straight forward planning, and the three fundamentals (competitive advantages, scenarios and strategies) involved in any strategic planning project. The use of shortened SSP version is more suitable for the development of strategic plans for small- and medium-size businesses. SSP has been applied to and tested on different businesses' subject issue and has been generated by the composition of the cause-and-effect relations of them.

Here, we have provided a new perspective and benefit for the strategic planners by introducing the newly generated shortened version of SSP and demonstrating its implementation on an entrepreneurial and new business called Visual Co. This will help SSP users to easily understand and apply this new methodology to any small- and medium-size businesses' strategic planning project. Though, the given case did not cover all the steps of a typical systematic strategic plan and use all the recommended techniques, it still reflected the basics. Some of the special working forms, in the forms of key documents and output, were used in applying the techniques in each step of the SSP pattern on the given case. 


\section{References}

1. Wickham PA (2004) Strategic entrepreneurship. Pearson Education Limited, London, UK.

2. Harrison JS, John CH (2001) Foundations in strategic management: Evansville. South-Western Publications, Tennessee, USA.

3. Muther R (2011) Planning by design, Institute for High Performance Planners. Kansas City, USA.

4. Porter ME (1998) Competitive strategy: Techniques for analyzing industries and competitors. Florence: The Free Press.

5. Vernon R (1979) The product cycle hypothesis in a new international environment. Oxford Bulletin of Economics and Statistics 41(4): 255 267.
6. Pearce J, Robinson R (2011) Strategic management: Formulation, implementation and control. Columbus, McGraw-Hill, USA.

7. Rasiel EM (1999) The McKinsey way. Columbus, McGraw-Hill, USA.

8. Wright P, Parnell J, Kroll M (1997) Strategic management: Concepts. Prentice Hall, New Jersey, USA.

9. Ansoff HI (1987) Corporate strategy (revised edn). Penguin Books, London, UK.

10. Keown AJ, Martin J (2001) Financial management: Principles and applications. Prentice Hall, New Jersey, USA.

11. Porter ME (2002) What is strategy? HBR on point enhanced edition. Watertown, Harvard Business School Press, USA.

12. Porter ME (1980) Competitive strategy. The Free Press, New York, USA. 